\title{
Personal Assessment Effects in Spreading the Quality of Culture Among Employees of the Special Care Organizations in Jordan
}

\author{
Dr. Ihsan Gdaifan Ali Alsaree' \\ $\mathrm{Al}$ al-Bayt University, Jordan
}

doi: 10.19044/esj.2016.v12n22p224 URL:http://dx.doi.org/10.19044/esj.2016.v12n22p224

\begin{abstract}
The aim of this study is to recognize the effect of self-organizational assessment in spreading quality culture among employees at special education organizations in Jordan. The study sample consisted of employees in 20 special education organizations that present services for persons with disability who were chosen randomly. The study instrument was designed. It consisted of 64 items distributed into seven domains. Also, their reliability and validity were calculated. The findings show that the level of selforganizational assessment in spreading quality culture among employees at special education organizations has an average which ranged from 2.89 to 2.61. Here, the domain of programs and services was in the first order with the highest average of 2.89. On the other hand, the domain of mixing was in the last order with an average of 2.61. In addition, the average of the effectiveness as whole was 2.73. Furthermore, the findings show that there were statistical differences $(a=0.05)$ due to the effect of the organization type. As a result, $\mathrm{T}$ value was 2.711 with a statistical significant of 0.007 in favor of the special organizations.
\end{abstract}

Keywords: Self-Assessment, special care organization, quality culture, autism, education

\section{Introduction}

Although there is a huge noticeable development in the field of special care sciences, the quality culture is not widely known among the special care organizations in developing countries. The Hashemite Kingdom of Jordan has witnessed a significant development in the fields of health, diagnostic of early signs of disabilities among the newborns, quality of good education, and social development related to the disabled people. Subsequently, this progress was noticed during the last few years, and highlighted by passing an act No (31) for the year 2007. Thus, the result was 
the establishment of The Supreme Council for the disabled. The main duties for the council were to design policies and to coordinate between all the agencies that were responsible for providing services for the disabled. Consequently, Jordan has also issued and implanted the national strategy for the disabled (http://www.mosd.gov.jo).

Jordan has achieved a noticeable progress in the human resources development for the disabled. This was achieved through the adherence to policies and regulations which enable the disabled to live a respectful life. Also, this could be achieved through providing the disabled with quantitatively and qualitatively expansion in education, health, and social services. However, this has helped the disabled to depend on themselves and to integrate themselves in the modern life. In 2007, Act No (31) states that the responsibilities of the council is to put down the required principles for the qualitative programmers and services introduced to the disabled people in accordance with other responsible agencies in order to achieve the council's vision and mission in developing a suitable accredited standards and indicators. Thus, this can suit the real operations of the council and the Jordanian culture to control the operations related to the organizations and special care centers programs. In the year 2009, the council launched the general criteria for accreditation. This was followed by special criteria for accreditation of the organizations and programs that works with people who suffer from mental disabilities and autism in Jordan for the year 2010 (The High Council for the Disabled, 2010).

Consequently, there are a lot of justifications to revise the working procedures and programs related to special care centers such as a lack of performance to work with disabled people, which were confirmed by a lot of studies on the necessity of self-Assessment for the organizations (Nasr, 2005).

\section{Study Problem}

Self-Assessment has a major role and direct effects on special care centers and the staff who work on them. Thus, the study is based on the effects of self-Assessment in spreading the quality culture among people who work in special care organizations in Jordan. Thus, the researcher chose a number of employees in special care organizations to answer the questions related to the study.

\section{Study Questions}

The study attempts to answer the following questions:

1. What is the level of self-organizational Assessment in spreading quality culture among employees of special care organizations from the view point of the study sample? 
2. Are there any significant difference $(\alpha=0.05)$ on the average views of the respondents about the efficiency of spreading quality culture among employees of special care organizations according to the type of the organization (public or private)?

\section{Significance of the Study}

Self-Assessment is an effective process used for helping the disabled to cope up with the environment that they live in and to spread the quality culture in special care organizations among the employees. Hence, the significance of the study could be summarized below:

The care of individuals through building care centers based on the rendered self-Assessment for the services and programs that may reflect the provided service quality.

Spreading the quality culture among employees of special care organizations through self-organizational process.

- $\quad$ Encouraging the role of special care organizations to work more effectively.

\section{Purpose of the Study}

The purpose of the study is to achieve the following objectives:

1- $\quad$ To identify the efficiency level of self-organizational Assessment in spreading the quality culture among employees of special care organizations in Jordan.

2- $\quad$ To identify the efficiency of self-organizational Assessment in spreading the quality culture among employees of both public and private organizations in Jordan.

\section{Definition of Terms}

Self-organizational Assessment: This is the work that is done by the organization management. It is used for collecting data and information about the organizational performance at the current time and comparing it with effective comprehensive standards.

Quality: According to the researcher, it is the availability of the questionnaire factors which was prepared by him that is based on the views of employees that work in special care organizations in Jordan.

Employees of the Special Care Organizations: The researcher referred to them as people who are officially working in special care organizations such as teachers and specialists in the first term of the academic year 2015 - 2016. 


\section{Limitations and Delimitations}

1. This study was limited to employees of special care units in $\mathrm{Al}$ Mafraq, Amman, and Al Karak governorates.

2. The study is limited to the time of performing the research at the first term of the academic year $2015-2016$.

3. The study is limited to organizations who deal with mental disorders, autism, and visual impairment.

\section{Review of Literature}

\section{Self-Assessment for Special Care Organizations}

Self-Assessment for special care organization involves the process of collecting data and information about the organization's performance at the current time; thus, it is used to compare it with effective comprehensive standards (Estes, 2004).

The objectives of self-Assessment for the special care organizations entail reaching out to a set of decisions (Lin, 2002). These decisions include: - To prepare the general performance matrix for the organization, which means, to help in putting the future plans which include the duties and activities of the organization in the future.

- $\quad$ To analyze and explain lack in the organization's performance.

\section{The Importance of Self-assessment for Special Care Organizations}

The important role of self- assessment in every organization comes from its cycle framework in improving the organization performance. Thus, this is because it helps us to identify the degree of Compatibility between the prevailing practices in the organizations and the comprehensive standards for different special care programs. In addition, it also helps to identify the strength and weakness points in order to reach the comprehensive standard programs for the special care organizations. Subsequently, it is used to determine when to start the effective plans to improve the services quality for the disabled (Al Srireh, 2009; Al Smadi \& Sartawi, 2001).

The study of Al Sofi (2004) shows the function of a working group from the sample of the population. They are:

- $\quad$ To plan for the study

- $\quad$ To identify the required information and data, the source of these information, and the data and ways of acquisition.

- $\quad$ Preparing the required tools that the employees are going to use during the study.

- $\quad$ Supervising the process of collecting the information during the analyzing stage.

During the study, it is very important for the organization's employees, teachers, the management, and parents to participate in the self- 
assessment organizational process through answering the questionnaires. The working group is, usually, divided into groups. Thus, each group is responsible for a specific job. These groups according to Al Srireh (2009) shows:

- $\quad$ The quality assurance team

- The organization's mission and vision quality team

- $\quad$ The organization's human resources quality team

- $\quad$ Organizational leadership quality team

- $\quad$ Social cooperation quality team

- $\quad$ Educational environment quality team

- $\quad$ Educational program quality team

- $\quad$ Teachers' performance quality team

\section{Steps for Self-assessment for the Organization}

In order to have a correct self-assessment process for the special care organizations, we must determine the number of steps that drives this process. These steps include (Crimmins \& Everett, 2001):

1. To form the study team and to follow the process of working with them.

2. Study planning

3. To form and train different working teams

4. To agree on the type of the information and data

5. Preparing tools to collect information

6. Implementing the study and obtaining the required information

7. Quantitative and qualitative treatment for the information and data

8. Writing the final report

\section{Quality}

The decision of being a highly reputable organization for any organization and implement the quality standards is considered an accumulative process that needs a continuous efforts. This is because it is not a routine work and it cannot be achieved within a short period of time (easy come easy go). As a result, it is very important to build the organization in the right way for the optimum benefits of all, especially for the disabled people.

\section{The Concept of Quality}

The word "quality" means the validity of a person or a thing, and it does not mean to be perfect. This is because it is a relative concept that differs between the beneficiary areas whether they are the clients, the designer, the society, or the organization. 
Quality, as a linguistic term, describes the degree of excellence of standard or the high quality of something.

According to Al Srireh (2009), it is very much related to good things, and it refers to some degrees or indicators that enable us to identify its construction. Therefore, the various products are usually complex and excellent.

The idea of quality appeared in the United States of America for the first time. However, it was first implemented in Japan. Many scholars agree that the Dimming was a pioneer in analyzing and presenting a suggested comprehensive program for the quality concept. It also shows how to manage it in the 1940s. His principles were the basis of many other workers in the field and it was included in designing any program for quality management. When Dimming was asked about the success of the program in Japan more than the United States, he answered "the difference is in the implementation process." Furthermore, there was a reward in japan after the name of Dimming was established in 1951. Thus, this was presented, for the first time, for companies who were successful in their programs for improving the quality standards.

The concept of quality was highly connected with industrial products and services as it helped the organizations to achieve success in the field of industrial completion. It was also connected with the Japanese products which were able to invade the world with high quality products.

Fisher (1996) sees quality as an abstract concept that means different things for individuals. In the field of industry and business, it means the excellence of qualities especially when compared with a special standard for the organization or the individual.

The International Standards Organization ISO (1997) sees quality as the overall characteristics for an entity (activity, a process, a product, or a system) reflected through its ability to satisfy the needs.

It is hard to have an exact definition for quality in the field of education, or to look for it from one single dimension. Therefore, it must be a comprehensive view, and should satisfy beneficiaries like decision makers, parents, university management, teachers, students, and different social organization.

According to Cheng, it is defined as a set of input and output items for an educational system that satisfy the needs of the people (Friwan, 2007).

Jawher (2000) defined Quality in education as the extent of achieving educational goals to satisfy the society. Thus, it is the first Beneficiary from educational institutions.

According to Bernum, there are three dimensions for Quality in education that we should give a special care to: 
a. Academic Dimension: The adherence of standards and levels of professional and academic research.

b. Individual Dimension: Educational institutions which is concerned about the personal growth of students by focusing on different cognitive skills and emotional needs.

c. Social Dimension: The adherence of the educational institutions in satisfying the needs of the components of the society (Al Jalaby, 2007).

Quality is the implementation of various sets of educational standards to increase the services level. Thus, it is achieved through choosing and implementing good inputs to satisfy the needs of the disabled and to increase their abilities to the highest extent.

Consequently, the review done by the disabled educational and professional office in New York university (2007) were aimed at developing quality indicators and educational guides in special care units. Thus, it is used as a field of training in special care organizations in New York. Also, it is used to guide the work in relation with the evaluation of professional development programs. In addition, it offers technical help to schools that deals with the disabled. The report, also, noted that the objective of using these guides is to offer support through the following: examining and evaluating the type of educational programs in the field of reading, behavioral intervention and support, offering special care services, identifying the needs, describing and planning activities to change practices, and to improve students' products. Furthermore, the components are:

1) Educational environment and special indicators: Designing and preparing the educational environment to satisfy individual needs and to share students with the ordinary educational environment including the curriculum, education, evaluation, and social activities depending on the individual's abilities.

2) Educational practices, planning, effective learning, and indicators related to it: Individual educational planning to determine the needs of the students; planned education guided by the objective by using direct learning strategies, educational skills, self-learning, executive jobs, learning strategies and effective values; and to make any required alteration depending on the individual needs.

3) The effective implementation of special care and the quality indicator: They comprises of using evaluation strategy based on the curriculum to monitor student's progress. Also, teachers are required to use official assessment strategies, record and analyze the data, and to employ that in educational planning.

There are assumptions that quality indicators has been built upon for special care programs, as mentioned in the report. However, they include the curriculum that is based on educational standards (special education and 
conventional education). A high quality education system for all students appreciates and values comprehensive education. However, special education is a service provided for the disabled and is not a place for extensive and individual learning.

\section{Previous Studies}

Al Dwaish (2011) conducted a study which is aimed at identifying the institutions that works with special care programs in KSA. The results revealed that the organizational structure is not flexible enough, unclear, shows a lack of management jobs, the employees are not selected with special procedures, the mission and vision are not clear, and there is a lack of experience for the principle in the integration process.

Al Zarea (2008) conducted a study which is aimed at building indicators to control quality in autism children programs and to identify the degree of compatibility to autism children centers in KSA. The study consisted of 20 public centers that provide services for male children who suffer from autism in the entire Kingdom. The results indicated that indicators for two factors of quality control factors were fully combatable. They are "the educational program and the individual educational plan, and the indicators of analyzing the practical behavior to alter behavior." In addition, there are indicators for four factors which are compatible with a medium degree. They include: indicators of learning and teaching strategies, the referential curriculum factor, indicators for the integration process factor, and indicators for the "assessment and diagnosis" factor. Subsequently, the other five indicators was complied with a lower degree which are: educational environment, the proposed program, the aiding services, and employees and family participation which was the less compatible indicators.

The study which was conducted by Robertson (2006) was aimed at investigating the effectiveness of quality control for special care office in education department in West Virginia. Thus, this is in accordance with the regulations and standards of the State. The result shows a progress in the provided special care services. However, this progress is related to individual educational plans and the management of the services provided for the disabled people. The results also revealed that the accountability system has fixed many previous problems that were mentioned in the review of the reports for the year 1996-1997. Thus, this was prepared by the educational department in the special care office.

The study conducted by Tietjens, McCray, and Co-chair (2005) was used to evaluate the programs and activities provided for disabled students in special care schools in Montana, Country Louis, in the USA. Here, Autism Program Quality Indicators (APQI) was built by Crimmins et al. (2001) and was applied in order to measure, evaluate, and analyze services, programs, 
and activities that were provided for the students who are suffering from autism. The measuring process was conducted during September 2014 February 2015. The sample comprised of 78 autistic students who were involved in the program. Thus, a one way analysis was chosen to analyze the program's data. The results revealed points of strength and weakness in the provided programs for the autistic students. Among the strong points was the appreciation of the parents to the teachers and the good relation between teachers and students. Furthermore, the weakness points include the lack of inclusiveness, the low level of technical support, the training, monitoring, self-evaluation process, and the classification of students to graded levels, especially in public programs.

Al Gazo and Al Grioty (2003) conducted a study aimed to examine what extent teachers of special education achieve the international standards. The sample number was 120 teachers who worked in schools and special care centers. The study answered the following questions: the extent to which teachers are working in special schools and centers in the United Arab Emirates, the Educational Standards for the Special Education Association (CEC), and the impact of the experience factor and sex factor in addition to the workplace factor. Thus, the results show no differences between males and females, and between workers in schools and centers. The study also showed that individuals who increase their expertise to ten years have the ability to achieve global standards than those who have less than ten years' experience of autistic from the viewpoint of parents and teachers.

La Paro (1999) indicates the use of a list of quality programs indicators for the purposes of the technical needs of organizations, individuals, and families with evaluating disabilities. This tool included 143 items recommended practices which have been organized. Furthermore, this list was developed with the help of 17 principals and the products of the family and the student. Through literatures related to disabilities, the services of the list finalized six dimensions as follows: (1) educational organizations (the philosophy of the organization and orientation, employees, programs, service delivery, integration, and evaluation); (2) classroom environment (organization, scheduling, data collection); (3) the student (mergers, utilities and amended, medical information, positivism); (4) family; (5) Education (educational strategies, communication, routine normal, autonomy/efficiency, feedback and evaluation); (6) integration and transition; (7) self-evaluation.

Al Bustanji (2007) conducted a study entitled “The Reality of Assessment in Special Education in Jordan.” However, it aimed to recognize the real evaluation in special education in Jordan. This is in terms of the objectives, the assessment teams, and the sources of information that is collected for the purposes of evaluation. Also, the side that covered the 
process of evaluation, testing, and standards were used in the evaluation process. It also includes the practices of subsequent assessment of formal assessment, methods alternate assessment, and the problems faced by those in charge of the evaluation process. The level of knowledge teachers special education have on the basics of the assessment process and on the knowledge of the differences in the level of their variables is dependent on educational qualification, experience, year of graduation, and age. Thus, the study sample consisted of 255 professors who are specialists in assessment. It also comprises of 301 teachers of special education, who work in the centers and special education schools that deal with people with learning difficulties, audio-visual, and motor and mental health centers that serve multiple categories and disability. The results showed that the objectives that the study sample seeks to achieve is "planning for teaching." Then, this "follows the progress and improvement in student performance." The results also show that a teacher of special education exists as a member of the assessment team in a high percentage. In addition, a high percentage of centers and schools that have been covered in the study have no assessment teams. This is because the evaluation process is done by one specialist due to the lack of appropriate assessment tools.

\section{Methods and Procedures}

This section provides a description of the members of the study. Thus, the study tool application procedures were followed by the researcher and statistical data processing.

\section{The Study Population and the Study Sample}

The study population comprises of all special education organizations that deal with special education in Jordan for the academic year (2015/2016). However, these include 48 organizations. The study sample was chosen randomly. As shown below, the sample included 20 organizations from special education organizations that provide services for persons with disabilities. Thus, this is shown in Table (1) below.

Table (1). Distribution of respondents by organization type variable

\begin{tabular}{|c|c|}
\hline \multicolumn{2}{|c|}{ Organization Type } \\
\hline Number & Group \\
\hline 14 & Public \\
\hline 6 & Private \\
\hline
\end{tabular}

Study Tools: In order to collect data to identify the impact of selforganizational assessment in spreading the quality culture among workers in special education organizations, the study tool consists of 64 items distributed on seven areas. These areas measure the impact of the selfassessment process in the dissemination of quality culture which is related to 
the Accreditation of the organizations and programs of persons with disabilities in Jordan. Also, it is issued by the Supreme Council for the Affairs of persons with disabilities. Furthermore, it was extracted and the reliability and validity of the tool was described as shown below:

Validity Tool: This was confirmed through submission to 8 university professors who are specialists in the field of special education. Hence, they work in Jordanian universities, where they made their views and comments on the appropriate paragraphs of the questionnaire, clarity of the wording, and the affiliation of its clauses. Then, they excluded, added, or modified paragraphs that were referred to. Thus, the questionnaire has a good degree of virtual honesty and sincerity has become arbitrators.

Reliability Tool: To ensure the reliability of the study tool, it has been verified that testing and re-testing the application of the test, and reapplying the test after two weeks on a sample consisted of 6 centers outside the study sample. Thus, the calculation of Pearson correlation coefficient between their estimates account for both times on the study tool as a whole.

Also, the coefficient reliability was calculated in the internal consistency manner according to Cronbach's alpha formula. Table 2 shows the internal consistency coefficient according to Cronbach alpha equation and Test - Retest Reliability. Hence, this is considered to be the appropriate values for the purposes of this study.

Table 2. Internal consistency coefficient Cronbach's alpha and Test - Retest Reliability in the areas of the total score

\begin{tabular}{|c|c|c|}
\hline Group & Test - Retest Reliability & Internal consistency \\
\hline Mission and vision & 0.87 & 0.90 \\
\hline Employees & 0.89 & 0.78 \\
\hline Programs and services & 0.90 & 0.87 \\
\hline Participation of the family & 0.91 & 0.88 \\
\hline Diagnosis & 0.89 & 0.78 \\
\hline Physical environment & 0.89 & 0.90 \\
\hline Integration & 0.91 & 0.88 \\
\hline Role as a whole & 0.89 & 0.94 \\
\hline
\end{tabular}

\section{The Study Procedures}

Consequently, the preparation of this study passes through several stages as shown below: arbitration.

1. Back to the literature of the subject and setup the tool and

2. The researcher applies for official approval from the relevant authorities for the application of the tool.

3. The researcher works with the help of a number of researchers to assist in the application, after being trained on how to use the tools. 
4. The researcher provides the researchers, who have been selected and trained with a study tool to apply and to collect the necessary data to achieve the objectives of the study.

5. The researchers visited the special education organizations to measure the degree of applicability of the dimensions (indicators), and the application of the tool. The study lasted one month from 10.01.2015 till 10.30.2015. Also, the researcher was able to have access to 22 organizations. Hence, they adopted 20 organizations and excluded 2 of them because of the lack of problems in completing the tool.

6. Analyzing the results to answer questions about the study.

\section{Statistical Analysis}

The researcher analyzed the data after collection. Then, it was subjected to these quantitative data analysis using statistical software (SPSS). Also, arithmetic means and standard deviations for the paragraphs of the special tool have been extracted to identify the impact of organizational selfassessment process in spreading quality culture among workers in special education organizations.

\section{Results}

This study aimed to identify the impact of organizational selfevaluation process in the deployment of quality among workers in special education organization. It is aimed at achieving the goal of the study. Consequently, a questionnaire was built to measure it. The results of the answer to the questions are shown below:

First Question: What are the levels of effectiveness of the organizational self-assessment in the spreading of quality culture among workers in special education organizations from the point of view of the study sample?

To answer this question, arithmetic means and standard deviations were extracted for the degree of exposure of the study sample. Thus, the table below illustrates this.

Table 3. Arithmetic means and standard deviations of the level of effectiveness of the organizational self-assessment in spreading quality culture among workers in special education organizations from the point of view of the study sample in descending order according to averages

\begin{tabular}{|c|c|c|c|c|}
\hline Rank & Number & Scope & $\begin{array}{c}\text { Arithmetic } \\
\text { Means }\end{array}$ & $\begin{array}{c}\text { Standard } \\
\text { Deviations }\end{array}$ \\
\hline 4 & 1 & Mission and vision & 2.72 & 0.60 \\
\hline 2 & 2 & Employees & 2.87 & 0.59 \\
\hline 1 & 3 & Services and programs & 2.89 & 0.49 \\
\hline 5 & 4 & Family participation & 2.66 & 0.49 \\
\hline 6 & 6 & Diagnosis & 2.62 & 0.46 \\
\hline 7 & 7 & Integration & 2.61 & 0.45 \\
\hline
\end{tabular}


Table (3) shows that the averages ranged between 2.89-2.61, where "services and programs," came in the first rank with the highest arithmetic average (2.89). On the other hand, "integration" came in the last place with an arithmetic mean of 2.61 and the arithmetic average of the role as a whole was 2.73 .

Second Question: "Is there a statistically significant differences $(\alpha=0.05)$ in the averages of the opinions of the respondents about the effectiveness of the organizational self-assessment in spreading the quality culture among workers in special education organizations due to the type of institution (public, private)?

To answer this question, arithmetic means and standard deviations were extracted based on the views of the respondents about the effectiveness of organizational self-assessment in spreading the quality culture among workers in special education organizations. These, however, are attributed to company type (public, private). Also, statistical differences between the arithmetic means $t$ test was used for independent data. Thus, the tables below illustrate this.

Table 4. Averages, standard deviations, and t test of the effects of company type on the opinions of respondents about the effectiveness of the organizational self-assessment

\begin{tabular}{|c|c|c|c|c|c|c|}
\hline $\begin{array}{c}\text { Type of } \\
\text { organization }\end{array}$ & Number & $\begin{array}{c}\text { Arithmetic } \\
\text { average }\end{array}$ & $\begin{array}{c}\text { Standard } \\
\text { deviation }\end{array}$ & $\begin{array}{c}\text { "t" } \\
\text { value }\end{array}$ & $\begin{array}{c}\text { Independent } \\
\text { degrees }\end{array}$ & $\begin{array}{c}\text { Statistical } \\
\text { significance }\end{array}$ \\
\hline Public & 14 & 2.74 & 0.55 & \multirow{2}{*}{2.711} & 998 & 0.007 \\
\hline Private & 6 & 2.83 & 0.44 & & 998 \\
\hline
\end{tabular}

Table (4) shows statistically significant differences $(\alpha=0.05)$ due to the impact of the type of organization. However, the value of $\mathrm{T}$ was 2.711. It has a statistically significance of 0.007 , and the differences were in favor of private organizations.

\section{Discussion, Findings, and Recommendations}

This part deals with the discussion of the results that were obtained by linking the quantitative results of the data on the impact of organizational self-assessment in spreading quality culture among workers in special education organizations in Jordan.

The First Question: Discuss the findings of the level of effectiveness of the organizational self-assessment in spreading quality culture among workers in special education organizations from the point of view of the study sample.

However, findings regarding the level of effectiveness of the organizational self-assessment in spreading quality culture among workers in special education organizations from the point of the study sample have averages which ranged from 2.89-2.61. Here, "services and programs" field 
came in the first rank with the highest arithmetic average of 2.89. On the other hand, "the integration and transition services" took the last place with an arithmetic mean of 2.61, and an arithmetic average based on the role as a whole with 2.73 .

Therefore, we noted here that the last place for the "integration of disabled children” does not mean the situation is very bad. Thus, this leads to pessimism, but it gives the impression that there is an acceptable degree of reasonable situation. In addition, it could be more optimistic of development and improvement in the future. The earlier findings can be explained by an existing awareness among workers on the importance of good quality services in the field of programs and services. Therefore, this makes those in charge of programs and services like the administrative, technical, and educational employees to not give much attention to the issue of quality control and the quality of these areas. This can be interpreted not to activate the technical supervision, follow-up, and evaluation of these programs and areas by the authorities concerned with the lack of vision regarding the quality control indicators. The consistent results of this study with the results of Al Zarea study (2008) shows that there are two indicators of the elements of quality control applied to a high degree. However, this is an "educational programs and an individual educational plan indicators, and it is consistent with the study of Taatganz, McCarry and Kochir (2005). Their study showed the results of the strengths and weaknesses of the programs offered to students. For example, parents noted a general standard of nobility among the teachers. However, weaknesses in the programs involve the lack of inclusiveness of the offered programs and the low level of technical support and training. The study is, also, consistent with the study of Bustanji (2007) which showed that the teacher of special education exists as a member of the assessment team in a high percentage. Bustanji further opines that a high percentage of centers and schools, that have been covered in the study, do not have an assessment teams. This is because the assessment is done by a single worker.

This study contradicts the study of Lin (2002) whose results showed that special education teachers in Taiwan enjoy a high level of skills and knowledge in the field of diagnosis and evaluation.

Second Question: Discusses the results related to the existence differences on the effectiveness of the organizational self-assessment in spreading quality culture among workers in special education organizations due to the type of organization (public, private).

The results indicated a presence of a statistically significant difference due to the impact of the type of the organization (public, private). Therefore, the value of " $t$ " is 2.711, has a statistically significant value of 0.007 , and the differences were in favor of private organizations. 
Furthermore, the researcher attributes that to the clarity of the private sector interests in quality. This is because it is linked to the process of attracting the largest number of children with disabilities, which brings them a better financial income. On the other hand, the public-sector workers do not find any job threats if there is no development in students' achievement and development. The workers in the private sector are specialized in special education and they realized the importance of the quality of services. In addition, they seek for it, and it is not the same case in the public sector. Consequently, no studies agree or disagree with the results of this study.

\section{Recommendations}

In light of the results of the current study, the researcher recommends the following:

- $\quad$ To conduct the study in other provinces.

- To conduct other studies which deal with other variables from different perspectives, such as the parents' perspective.

- $\quad$ The Ministry of Social Development and the Supreme Council for the disabled should hold workshops and training sessions devoted to the importance of quality in providing services to persons with disabilities.

\section{References:}

Al Sofi \& Hamdan (2004). The concept of quality and its components in Islam, Quality in Higher Education, Issue 1, the Islamic University of Gaza. Abdul Salam \& Friwan (2007). Quality in Higher Education and the Arab world, the journal of Arab Universities Union, No. 4, April.

Akef, Al Zoubi, Sohail, Abdul Rahman, Majdoleen, \& Khatib (2012). The evaluation of Programs and services in intellectual disabilities organizations and centers in the light of international standards, the International Review of Education, Vol. 1, No. 3.

Al Duweish \& Abdulaziz (2011). Depicting a proposal for the development of school administrations thereto special education programs in the light of global trends, unpublished PhD Thesis, University of Imam Muhammad bin Saud Islamic University, Saudi Arabia.

Al Bustanji \& Murad (2007). Reality of the Assessment in Special Education in Jordan, Ph.D. thesis unpublished, University of Jordan, Amman, Jordan.

Al Gazo, Imad, Al Qaryouti, \& Ibrahim (2003). The extent to which special education teachers in the UAE applicable to the standards of the Special Education Association (CEC). Teacher preparation for the Third Millennium Conference, College of Education, UAE University.

Al Jalabi \& Sawsen (2007). Total quality standards in Arab universities, Journal of Association of Arab Universities, The fourth release. April 
Al Zarea \& Nayef (2008). Quality controlindicators in educational programs for children with autism and the degree compatibility to the autism centers in the Kingdom of Saudi Arabia. Unpublished Ph.D. Thesis., University of Jordan, Amman.

Alkhrmi \& Sahar (2003). An evaluation study of special education centers in the city of Riyadh. Journal of Educational and Psychological Sciences, Vol. V, No. 4, University of Bahrain.

Crimmins, D., Durand, V., Kaufman, T. \& Everett, J. (2001). Autism program quality indicators: A self-review and quality improvement guide for schools and programs serving students with autism spectrum disorders. Albany, New York: New York State Education Department.

Estes, M. B. (2004). Choice for all, Charter Schools and students with Special Needs, Journal of Special Education.

Fisher \& Bary (1996). Developing An ISO 9000 Quality System,U.K. Lough broraygh University.

Jawher \& Salah al-Din (2000). Methods and techniques of educational administration in the light of the information and communication revolution, Journal of Education, College of Education, Al-Azhar University, the $105^{\text {th }}$ release.

La Paro et al. (1999). Using a quality indicator checklist to assess technical needs for individuals and families.eric:d373460

Lin, T. (2002). Knowledge / skills needed by special education teachers in central Taiwan elemantary schools, Unpublished Doctoral Dissertation. Kentacky : University of Louisville

Samadi, Jameel, Sartawi, \& Abdul Aziz (2001). Assessing the effectiveness of special education centers in the United Arab Emirates. King Saud University magazine book No 13, pp. 129-165.

Saraireh \& Khaled (2009). The comprehensive quality management in higher education institutions, Petra conference, a working paper at the $16^{\text {th }}$ training conference "Features and prospects for comprehensive quality in higher education, 21 of May 2009, Amman, Jordan.

Tietjens, McCray, \& Co-chair, D (2005, August). Program evaluation for students with autism. Special School District of St. Louis County Retrieved from: htt://www.ssd.k12.mo.us/.

http://www.mosd.gov.jo 